\title{
Criação do banco de instrumentais odontológicos de uma universidade pública como instrumento democrático na formação em saúde
}

\author{
Michelle Cecille Bandeira Teixeira*; Mariana Campos Baptista da Silva**; Andréa Neiva da Silva*** \\ * Doutora em Bioética, Ética Aplicada e Saúde Coletiva, \\ Professora Adjunta, Departamento Saúde e Sociedade, \\ Instituto de Saúde Coletiva, Universidade Federal \\ Fluminense \\ ** Estudante, Graduação em Odontologia, Universidade \\ Federal Fluminense \\ *** Doutora em Saúde Pública, Professora Associada, \\ Departamento Saúde e Sociedade, Instituto de Saúde \\ Coletiva, Universidade Federal Fluminense
}

Recebido: 03/11/2020. Aprovado: 20/02/2021.

\begin{abstract}
RESUMO
O artigo descreve e analisa a experiência de criação do Banco de Instrumentais Odontológicos da Faculdade de Odontologia da Faculdade de Odontologia da Universidade Federal Fluminense (BIOFO-UFF), campus Niterói, Brasil, na perspectiva de promoção da equidade. O BIOFO-UFF viabiliza o acesso dos estudantes em situação de vulnerabilidade socioeconômica aos instrumentais necessários para as atividades clínicas e laboratoriais durante a formação profissional em Odontologia. O presente artigo tem por objetivo descrever o processo de criação e funcionamento do BIOFO-UFF, destacando seu potencial para reduzir a retenção e a evasão acadêmica. Salienta-se a relevância da iniciativa enquanto dispositivo pedagógico a partir de três perspectivas: responsabilidade social da instituição, formação cidadã, ética e solidária e apoio à inclusão e equidade socioeconômica. Além de apontar os limites da estratégia, o artigo ressalta a importância do envolvimento da comunidade acadêmica na construção de práticas mais democráticas e equitativas na formação em Odontologia. Finalmente, é destacada a relevância que o BIOFO-UFF pode alcançar no contexto de pós-pandemia de COVID-19.
\end{abstract}

Descritores: Vulnerabilidade Social. Equidade. Educação em Odontologia. 


\section{INTRODUÇÃO}

A Lei 12.711 de 2012, chamada Lei das Cotas, que garante a reserva de vagas nas universidades federais a estudantes oriundos integralmente do ensino médio público para ingresso nas universidades federais de ensino ${ }^{1}$, determinou um aumento da diversidade social, racial e cultural entre os acadêmicos nos diferentes cursos universitários $^{2}$. A política de cotas representou um marco histórico no enfrentamento da exclusão racial e social do sistema educacional no Brasil ${ }^{3}$ especialmente nos cursos de maior concorrência e considerados de maior prestígio social, como Engenharia, Medicina e Odontologia ${ }^{4}$.

No caso da Odontologia, o impacto das cotas determinou mudanças importantes no perfil socioeconômico dos acadêmicos do curso haja vista que, historicamente, essa graduação tem sido cursada, em sua maioria, por estudantes de cor branca e pertencentes às classes sociais média e alta $^{5,6}$. Para os estudantes de baixa renda, as dificuldades ao longo do curso incluem gastos com alimentação, deslocamento até a universidade, aquisição de livros, fotocópias e, em muitos casos, custos com moradia para aqueles estudantes oriundos de outros munícipios ou estados.

De forma semelhante às instituições privadas, a graduação em Odontologia em instituições públicas exige dos estudantes aquisição de instrumentais odontológicos para uso laboratorial e clínico durante o curso. Além disso, os cursos normalmente demandam dedicação integral dos estudantes, envolvendo pelos menos dois turnos diários com disciplinas para que a integralização curricular seja alcançada no período estipulado pela universidade.

A extensa carga horária a ser cumprida pelos estudantes dificulta ou, na maioria das vezes, impede que o discente desempenhe atividades laborais para arcar com os custos decorrentes da graduação. Soma-se a isto, a exigência de vestuário adequado, como jaleco com manga, sapato branco fechado, roupa branca e uma grande quantidade de material de consumo descartável, como luvas, máscaras e gorros, entre outros ${ }^{7,8}$. Todos esses fatores contribuem para que a graduação em Odontologia, mesmo nas instituições públicas de ensino superior, implique em elevados gastos financeiros por parte dos estudantes.

Nesse contexto, muitas vezes os programas de assistência estudantil são insuficientes para garantir a permanência dos acadêmicos no curso de Odontologia. Além de ser um curso integral, estima-se que o valor gasto com instrumentais odontológicos durante toda a graduação varie entre $\mathrm{R} \$ 12.000,00$ e $\mathrm{R} \$ 15.000,00$ reais $^{8}$.

Entretanto, a universidade tem a responsabilidade de atuar no sentido de promover a equidade entre os estudantes para que estes possam desfrutar de oportunidades justas durante a formação. Estudos anteriores ${ }^{7,9}$ corroboram esta afirmativa, enfatizando a necessidade da deselitização da Odontologia, para desmitificar o preceito de que, para se graduar como cirurgiãodentista, deve-se possuir alta renda familiar para arcar com os custos financeiros ao longo da graduação.

Quando os estudantes de baixa renda transpõem barreiras e acessam um curso oneroso como o de Odontologia, o próprio processo educativo gera iniquidades entre aqueles que podem pagar os instrumentais solicitados e aqueles que não podem, criando arranjos sociais particulares relacionados a poder e privilégio. Portanto, os próprios arranjos institucionais precisam gerar meios que ofereçam a este estudante genuínas oportunidades para cursar sua graduação. Para tanto, é preciso promover programas de inclusão, gestão, organização curricular e outras ações que o coletivo acadêmico considere necessários para colocar em prática uma formação mais equitativa ou inclusiva ${ }^{10}$.

Determinados grupos como classe social e raça geram experiências diferentes e desiguais 
no formar-se profissional de saúde. Estas desigualdades exacerbam-se em um curso de status social alto, tal como Odontologia, se reproduzindo em um ambiente que exclui socialmente. Com a implementação das cotas, o desafio passa a ser o de afirmar a diversidade social e racial no cotidiano acadêmico. É papel do curso de Odontologia trabalhar em prol desta diversidade, transformando-a em uma oportunidade de ensinar a seus estudantes alteridade, reconhecimento, respeito, práticas equitativas e visão crítica? .

Neste sentido, na Faculdade de Odontologia da Universidade Federal Fluminense, campus Niterói, foi desenvolvido um sistema de empréstimo de instrumentais odontológicos, na qualidade de ação extensionista vinculada ao projeto "Dar Voz: o estudante de Odontologia e seu cotidiano universitário". O presente estudo tem por objetivo descrever e refletir sobre a experiência de elaboração e implementação deste banco de instrumentais odontológicos, seus desafios e potencialidades.

\section{RELATO DE EXPERIÊNCIA}

Trata-se de um relato de experiência reflexivo, no qual se descreve o desenvolvimento do Banco de Instrumentais Odontológicos da Faculdade de Odontologia da Universidade Federal Fluminense (BIOFO-UFF) iniciado no ano de 2019.

A Faculdade de Odontologia da UFF (FOUFF), localiza-se na cidade de Niterói, município da Região Metropolitana do estado do Rio de Janeiro. O curso apresenta carga horária obrigatória de 4035 horas e o período para integralização curricular previsto é de 9 semestres. A matriz curricular inclui 14 disciplinas laboratoriais e 15 de caráter clínico que demandam, necessariamente, a aquisição de instrumentais/materiais odontológicos pelos estudantes $^{11}$. No segundo semestre de 2018 havia 335 estudantes matriculados na graduação em
Odontologia $^{12}$.

Estudo recente demonstrou que $42,3 \%$ dos estudantes de Odontologia da instituição eram beneficiários de políticas afirmativas e que cerca de $24 \%$ dos graduandos possuíam renda familiar mensal de até 3 salários mínimos. O estudo também apontou que a maioria dos estudantes (88\%) não exercia nenhum tipo de atividade laborativa em virtude da necessidade de dedicação integral ao curso $^{13}$.

O público alvo do projeto em tela são estudantes em situação de vulnerabilidade socioeconômica do $1^{\circ}$ ao $9^{\circ}$ período da graduação de Odontologia da FO-UFF.

A idealização do projeto surgiu em 2018 diante da constante queixa dos estudantes de Odontologia sobre os elevados custos dos instrumentais a serem adquiridos para as disciplinas laboratoriais e clínicas da FO-UFF. O tema "quantidade e custos dos instrumentais odontológicos" era recorrente nos encontros com a comunidade acadêmica promovidos pelo projeto de extensão "Dar Voz: o estudante de Odontologia e seu cotidiano universitário" ao longo de 2018. O referido projeto é integrado por docentes e discentes e tem por objetivo promover debates democráticos junto à comunidade acadêmica com a finalidade de discutir questões e propor intervenções voltadas a melhorar o cotidiano universitário.

O BIOFO-UFF foi, portanto, desenvolvido e levado a efeito na qualidade de ação extensionista no escopo do projeto de extensão "Dar Voz". A equipe responsável pelo BIOFO-UFF inclui duas docentes, sendo uma delas a coordenadora do projeto, e três estudantes de graduação de Odontologia. Apesar de não fazer parte da equipe de execução, discentes membros do Diretório Acadêmico da FO-UFF apoiaram o projeto em todas as suas etapas de elaboração.

As etapas de idealização e implementação do BIOFO-UFF são descritas no quadro 1. 
Campanha de arrecadação de instrumentais. A primeira etapa aconteceu no primeiro semestre de 2019 com a elaboração de uma campanha para sensibilização de cirurgiões-dentistas, docentes e estudantes com objetivo de estimular a doação de instrumentais odontológicos ao BIOFO-UFF, que se encontrava em fase de estruturação. A equipe do projeto de extensão "Dar Voz" elaborou e veiculou cartazes em suas redes sociais e canais de comunicação interpessoal objetivando mobilizar não apenas a comunidade acadêmica, mas sobretudo cirurgiões-dentistas com atuação fora da instituição. Para facilitar o contato dos possíveis doadores com os integrantes da equipe vinculada ao banco, foram disponibilizados um número de celular (com o aplicativo WhatsApp Messenger ${ }^{\circledR}$ instalado) e um e-mail.

Coleta de Instrumentais. Os instrumentais foram recolhidos nas residências ou locais de trabalho dos doadores e, em algumas situações, foram entregues pelos doadores diretamente aos membros da equipe de colaboradores do BIOFO-UFF.

Limpeza, desinfecção, esterilização e estocagem dos instrumentais coletados. Os instrumentais recebidos foram devidamente limpos, desinfectados e esterilizados em autoclave seguindo todo protocolo de biossegurança ${ }^{14}$ Em seguida os instrumentais identificados foram estocados em armários apropriados dentro do setor de almoxarifado da própria faculdade.

Catalogação dos instrumentais. Uma vez esterilizados, cada instrumental recebido foi devidamente catalogado. Os instrumentais foram agrupados por nomenclatura, número, quantidade, marca e disciplina solicitante e passaram a compor a planilha do acervo do BIOFO-UFF montada no programa Excel®.

Elaboração do edital de empréstimo de instrumentais. O próximo passo do projeto incluiu a realização de reuniões da equipe do projeto com o Diretório Acadêmico para elaboração das bases do edital de convocação para a inscrição de candidatos ao empréstimo de instrumentais odontológicos. O edital continha o detalhamento das regras de empréstimo, renovação e devolução, bem como os pré-requisitos para candidatar-se, considerando a necessidade de oferta prioritária aos estudantes socialmente vulneráveis. Desta forma, a prioridade é dada ao estudante que ingressou no curso de Odontologia da FO-UFF pelo Sistema de Reserva de Vagas/Política de Ações Afirmativas no SiSU (Sistema de Seleção Unificada) conforme os critérios da Pró-Reitoria de Graduação (PROGRAD). Os critérios são divididos em 8 categorias que se interseccionam, considerando os grupos socialmente vulneráveis, a saber: étnicos (indígenas), raciais (pardos e pretos), classe social (renda familiar bruta per capita igual ou inferior a 1,5 salário mínimo e ensino médio em escola pública) e candidatos com deficiência que são de famílias com renda igual ou inferior a 1,5 salário mínimo. Embora candidatos que se enquadrem nesses critérios tenham prioridade na tomada de empréstimo de instrumentais, também são considerados elegíveis estudantes que comprovem vulnerabilidade socioeconômica através de documentação prevista no edital.

Divulgação do edital. Foram produzidos banners (físicos e digitais) a fim de anunciar o período de abertura das inscrições. As redes sociais do projeto de extensão "Dar Voz" e do Diretório Acadêmico foram os principais veículos de divulgação. Nos banners físicos, fixados nos murais de todos os andares do prédio da Faculdade de Odontologia, foi inserido um código de barras ( $Q R$ code) que, quando escaneado, direcionava ao edital do processo seletivo.

Seleção dos candidatos. Para a seleção dos estudantes inscritos foram seguidos os critérios estabelecidos no edital. A banca de seleção foi composta pelas docentes e acadêmicas também vinculadas ao referido projeto. A lista dos candidatos selecionados foi divulgada de forma individual por e-mail para os inscritos. Tendo sido o candidato selecionado, este teve 15 dias para preencher uma planilha com todos os instrumentais de que necessitava empréstimo e encaminhá-la também por e-mail para o BIOFO[texto ocultado].

Simulação em planilhas da distribuição dos instrumentais entre os candidatos. Nessa etapa todas as demandas por instrumentais foram inseridas na planilha que continha o acervo do BIOFO-UFF. Em seguida as demandas de cada candidato foram comparadas com a quantidade disponível no banco. Dessa forma, foi possível identificar algumas situações em que a demanda foi superior à oferta. Nesses casos, foram assinalados os casos de disputa para que pudessem ser solucionadas na presença dos estudantes envolvidos.

Simulação da distribuição dos instrumentais. Previamente à entrega propriamente dita dos instrumentais, a equipe do projeto reuniu-se com todos os candidatos selecionados em sala reservada com intuito de dar transparência ao processo de empréstimo. A planilha com a simulação dos empréstimos foi exibida em projetor multimídia para todos os presentes. Nos casos em que a demanda de instrumentais pelos candidatos superava a oferta, os envolvidos na disputa decidiram de forma consensual e amigável aquele que seria o beneficiado, respeitando o grau de vulnerabilidade expressada espontaneamente pelos candidatos. Vale destacar que os casos em que houve disputas por instrumentais foram raros e a forma consensual de resolução mostrou-se adequada e garantiu a transparência ao processo de empréstimo.

Entrega dos instrumentais. A distribuição dos instrumentais aconteceu na segunda semana de aulas do segundo semestre letivo de 2019 e foi realizada mediante a apresentação pelos estudantes do plano de estudos referente ao semestre. Dessa forma, o estudante comprovava sua inscrição nas disciplinas cujos instrumentais estavam sendo tomados para empréstimo. Na ocasião era assinado o Termo de Responsabilidade tal como previsto no edital. Para a efetivação do empréstimo de instrumentais, cada candidato assinou esse termo de responsabilidade no qual se comprometia a devolvê-los ao término de seu uso (geralmente no final do curso) devidamente esterilizados e em boas condições.

Renovação do empréstimo. A cada semestre era facultado aos estudantes a renovação dos empréstimos e a concorrência a novo edital para se beneficiar de nova cessão de instrumentais de acordo as necessidades das futuras disciplinas que tinham intenção de cursar.

Quadro 1. Etapas de idealização e implementação do BIOFO-UFF

Até o momento foram realizados dois editais de empréstimo do BIOFO-UFF e todos os estudantes que se inscreveram foram beneficiados em praticamente todas as suas demandas por 
instrumentais. É preciso salientar que o projeto pode estar contribuindo para diminuir a retenção na medida em que evita o trancamento da matrícula pelos estudantes movidos pela necessidade de trabalhar para levantar recursos financeiros. Já foi verificado que o trancamento do curso de Odontologia em outras universidades públicas para fins laborais ou até mesmo a evasão podem ter como causa principal o custo financeiro dos instrumentais odontológicos ${ }^{7,8}$.

Desta forma, é possível que o projeto esteja também colaborando para a permanência estudantil, já que os programas de assistência estudantil da universidade não são suficientes para cobrir grande parte dos custos dessa graduação.

Apesar disto, chamou a atenção o número relativamente baixo de estudantes que se inscreveram no BIOFO-UFF nos dois editais já realizados. Atualmente, são 23 estudantes beneficiados, um número aquém do esperado e aquém do que o acervo do banco é capaz de atender. Uma explicação possível pode estar na própria norma elitizada do curso e exigência de marca de instrumental que faz com que os estudantes se sintam constrangidos ou com receio em utilizar os instrumentais que não são novos ou não são da marca solicitada. Os aspectos de integração social e formação de identidades perante seus colegas e seus professores tornam-se uma exigência alta para estudantes de classe social baixa e negros, ainda minorias dentro de um curso de alto status social.

Outra explicação pode estar relacionada com o fato de estudantes de baixa renda sequer cogitarem a possibilidade de se inscreverem no curso de Odontologia. Já foi apontada a existência de um funil social de entrada no curso de Odontologia, que provoca uma dificuldade em sua democratização, uma vez que, ao ser considerado um curso caro e elitizado, jovens de baixa renda hesitam em se candidatar, ainda que em universidades públicas ${ }^{9}$.
Dados do Exame Nacional de Desempenho dos Estudantes (ENADE) comprovam que o acesso à educação universitária é desigual em diferentes cursos, demonstrando a distância que existe entre o que preconiza a Lei 12.711/2012 (50\% das vagas de cada curso preenchidas por cotas) e o que ocorre em alguns cursos de graduação do país ${ }^{15}$. Em recente levantamento sobre a estratificação socioeconômica das carreiras universitárias no Brasil, o curso de Odontologia aparece em terceiro lugar (atrás somente da graduação em Medicina e Relações Internacionais) entre aqueles com mais chance de incluir pessoas de origem socioeconômica alta ${ }^{16}$. Entretanto, a realidade da FO-UFF parece estar mais próxima ao preconizado pela lei, na medida em que $42,3 \%$ dos acadêmicos declararam ser beneficiários das políticas de ações afirmativas no ano de $2019^{13}$.

Supõem-se, neste sentido, que os beneficiários de ações afirmativas do curso de Odontologia devido à renda baixa não representem um número expressivo dentro da universidade. Ademais, é possível que os estudantes, ainda que em situação socioeconômica pouco favorável, sintam-se constrangidos em não apresentar as marcas de instrumentais exigidas em algumas listas e prefiram levantar recursos financeiros às custas de algum grau de endividamento familiar. Essas hipóteses necessitam ser investigadas em pesquisas futuras.

Percebeu-se que o engajamento da comunidade acadêmica na divulgação das campanhas para arrecadação de instrumentais gerou resultados positivos, incentivando a doação voluntária por ex-alunos da universidade, cirurgiões-dentistas não mais atuantes na clínica odontológica e docentes. De tal forma, o acervo do BIOFO-UFF conta atualmente com 1736 instrumentais, viabilizando o empréstimo para diferentes grupos de estudantes vulneráveis vinculados ao curso.

É preciso ressaltar que ações voltadas à 
permanência de estudantes de baixa renda na graduação de Odontologia pode ser promissora quando envolve a comunidade acadêmica como um todo. Além de produtora crítica do conhecimento, a universidade enquanto instituição deve ser capaz de assegurar o futuro de seus estudantes e assumir sua responsabilidade social e ética na construção de uma sociedade justa e inclusiva $^{17}$.

Também merece destaque no desenvolvimento do presente projeto o protagonismo do Diretório Acadêmico, que participou ativamente na sua estruturação, com especial atuação na catalogação dos instrumentais doados e na elaboração do edital. A participação discente e do diretório é essencial na construção de práticas mais democráticas e equitativas na formação universitária ${ }^{9}$.

Além desta perspectiva pragmática de reduzir os custos financeiros dos acadêmicos na aquisição dos instrumentais, a proposta de uma lista básica de instrumentais para a graduação também segue na direção de uma ruptura com uma cultura elitista que normatiza modos de agir da comunidade acadêmica. Referimos, portanto, à existência de uma determinada norma social que atravessa qualquer arranjo educacional no curso de Odontologia, seja pedagógico, curricular, organizacional ou político. É preciso, portanto, trabalhar para que os estudantes que estão à margem do seu curso em função desta norma social elitista, passem a ser incluídos e reconhecidos inclusive como atores necessários ao aprendizado sobre diversidade e alteridade através de processos pedagógicos que afirmem a diversidade ${ }^{9}$.

Nesta perspectiva, é fundamental o desenvolvimento de projetos que tem como enfoque a prática equitativa. Cabe aos professores se manterem mais atentos e sensíveis a estas diferenças e estarem dispostos a enfrentar os desafios das relações de poder e conflitos que rodeiam uma prática que busca diminuir desigualdades em um contexto elitizado.

Pode-se perceber que esta norma social do curso culmina em práticas que aumentam as desigualdades entre os estudantes, como a exigência indiscriminada de uma lista de material odontológico, indo na direção contrária de se ter uma norma social baseada em práticas democráticas e equitativas. Isto acaba se refletindo em exigência por marcas de instrumentais mais caras ou materiais e instrumentais que, muitas vezes, sequer são utilizados e poderiam ser de uso coletivo.

Assim, a partir de seu cunho social e inclusivo, o BIOFO-UFF pretende incorporar outras práticas relacionadas à democratização do curso, tal como a sugestão da revisão das listas de materiais e instrumentais solicitadas pelas disciplinas. Desta forma, a próxima ação a ser desenvolvida pelo projeto inclui a proposição de uma lista de instrumentais essenciais para a formação em Odontologia sugerida pela Associação Brasileira de Ensino Odontológico (ABENO) ${ }^{18}$. Essa ação teria efeito não apenas sobre os estudantes que ingressaram na universidade pelas ações afirmativas como também sobre vários graduandos que apresentam dificuldades financeiras na compra de instrumentais.

Outra ação que o BIOFO-UFF tem desencadeado, especialmente tendo a coordenação de curso como mediadora, é o estabelecimento de um diálogo com a comunidade docente, de modo a envolvê-la com o projeto e evitar possíveis constrangimentos dos estudantes que usam os instrumentais do banco, os quais podem não ser da marca indicada nas listas de materiais disciplinares.

Estudo recente que descreveu a experiência de beneficiários de um programa de empréstimo de instrumental odontológico relatou casos de humilhação e discriminação dos estudantes por parte de professores da instituição de ensino ${ }^{19}$. Esses fatos foram motivados pois os instrumentais 
tomados de empréstimo estavam fora do padrão exigido por algumas disciplinas, embora em boas condições de uso.

A relevância do banco de instrumentais odontológicos extrapola o aspecto material, que $a$ priori já é importante, por garantir empréstimo dos instrumentais a quem não teria condições financeiras de aquisição. Entretanto, além desse aspecto material, iniciativas como o BIOFO-UFF tem como respostas aventar novas possibilidades quanto ao seu papel social. Na experiência aqui descrita, buscou-se mobilizar a comunidade acadêmica na percepção das diferenças sociais que existem entre os colegas, como um verdadeiro exercício de agir pela equidade, considerando sua relevância e necessidade.

Modos sobre como a sociedade pode se tornar mais igualitária tomam forma em questões educacionais sobre os conhecimentos, atitudes e experiências pelos quais passam os estudantes durante seu processo de formação. São questões que passam a fazer parte da aprendizagem do estudante, pois não desvinculamos uma pedagogia de conhecer e saber de uma pedagogia de ser e fazer, numa visão da aprendizagem que reúne um projeto ontológico e um projeto epistemológico ${ }^{20}$.

O banco de instrumentais odontológicos, como uma proposta construída horizontalmente, reunindo docentes e discentes está alinhado com o compromisso ético, humanístico e social, centrado no aluno enquanto agente em sua formação através de uma articulação entre ensino, pesquisa e extensão/assistência. Portanto, o BIOFO-UFF investe no modelo pedagógico como espaço de constituição de agentes sociais e não como mero adestramento para o mercado de trabalho ${ }^{8}$.

Cabe aqui enfatizar a dimensão pedagógica do BIOFO-UFF na medida em que consideramos de igual importância a educação moral e cultural dos estudantes, onde a graduação pode ser um espaço de experiências significativas de solidariedade, humanidade e práxis equitativa para uma construção sociocultural de personalidade moral. Conforme afirmam Finkler e Negreiros (2018) ${ }^{21}$, tal abordagem extrapola a formação profissional dos cursos superiores e alcança a formação ética a partir de como os próprios estudantes vivenciam sua trajetória acadêmica.

A rede de interações que ocorre na universidade é onde os indivíduos formam e transformam suas identidades e abraçam ou rejeitam ideias, dão significados ao seu exercício enquanto parte de uma comunidade discente universitária e também constroem suas perspectivas de atuação como um futuro profissional de sua área, dentro da representação de categoria profissional construída a partir da enculturação de suas características e modos de $\operatorname{agir}^{22}$.

Um eixo necessário a esta formação ética é a prática da alteridade, enquanto o reconhecimento do outro como diferente em uma relação pautada pelo respeito. O BIOFO-UFF tem a potencialidade de trazer esta prática mais ativa, inserida na vivência acadêmica, com o entendimento que os estudantes de graduação são adultos em processo de investimento das suas identidades. Portanto, é imprescindível buscar verdadeiras experiências de intersubjetividade nestas relações para o desenvolvimento humanístico destes estudantes para que, ao invés de aprender a desigualdade e meritocracia, os estudantes aprendam - enquanto vivenciam práticas equitativas - a solidariedade e a responsabilidade social e participativa, por meio de uma persistente reflexão crítica nas tomadas de decisão e perante o diferente ${ }^{23}$.

\section{CONSIDERAÇÕES FINAIS}

Foi possível perceber que a criação do BIOFO-UFF está alinhada com três perspectivas: a responsabilidade social da instituição; a formação cidadã e ética; e o apoio à inclusão e equidade socioeconômica. A primeira perspectiva, da responsabilidade social da instituição, representada 
pelo desenvolvimento do projeto na qualidade de ação extensionista universitária, refere-se ao dever institucional em promover o acesso e a permanência de estudantes de baixa renda no curso. Esse aspecto é ainda mais relevante por se tratar de uma instituição pública, o que amplifica esta responsabilidade. A segunda perspectiva, de formação cidadã e ética, se deu na medida em que o BIOFO-UFF traz para dentro do cotidiano do ensino superior a necessidade de se ter uma prática equitativa, solidária, colaborativa e de consciência social e política, o que Puig e Martín (2015) ${ }^{24}$ chamam de cultura em valores. A terceira perspectiva, de apoio à inclusão e equidade socioeconômica, está evidente na medida em que o empréstimo de instrumentais pelo BIOFO-UFF tem o potencial de evitar o trancamento e a evasão de estudantes com dificuldades financeiras.

A experiência do BIOFO-UFF demonstrou que uma construção coletiva que envolva toda a representação da comunidade acadêmica é necessária e que seu alcance está para além da assistência estudantil. Sua importância é inegável também como dispositivo pedagógico de formação ética e solidária para a formação.

É preciso destacar que a pandemia de COVID19 tem gerado consequências importantes sobre a renda familiar dos brasileiros. Os impactos financeiros desta crise sanitária nas famílias de menor renda e naqueles trabalhadores informais tem sido desproporcionalmente maiores em relação ao restante da população. Muito possivelmente, estudantes que, antes da pandemia, teriam os custos com instrumentais financiados por suas famílias, poderão não estar mais aptos a suportar esses gastos diante de um futuro retorno às disciplinas clínicas e laboratoriais. Desta forma, o BIOFO-UFF poderá representar uma alternativa promissora para os estudantes mais afetados socioeconomicamente pela pandemia.

Espera-se que este relato de experiência possa contribuir para que outras instituições elaborem seus próprios sistemas de empréstimo, considerando ser uma ação que faz parte dos esforços em direção à construção de um curso mais democrático, menos elitista, mais equitativo e que afirme a diversidade socioeconômica de sua comunidade acadêmica.

\section{ABSTRACT \\ Development of the Dental Instruments Bank in a public university as a democratic tool in academic health training: experience report}

This article describes the experience of the development of the Dental Instruments Bank at the Dental School of the Fluminense Federal University (DIBDSUFF), Niterói campus, Brazil, considering the equity promotion perspective. The DIBDSUFF promotes access for socially vulnerable students to the necessary dental instruments required for clinical and laboratory activities during the professional training in Dentistry. This paper aims to describe the development and working processes of the DIBDSUFF highlighting its potential to enhance academic retention and to reduce dropout rates. It emphasizes the relevance of this initiative as a pedagogical tool considering three perspectives as follows: (i) the institution's social responsibility, (ii) citizen, ethic and solidarity education, and (iii) support for social inclusion and socioeconomic equity. As well as pointing out the limits of this strategy, the present manuscript emphasizes the importance of the involvement of academic community in building up more democratic and equitable practices in dentistry training. Finally, the relevance that the instrument bank can achieve in the postpandemic context of COVID-19 is highlighted.

Descriptors: Social Vulnerability. Inclusion. Healthcare Education. Dentistry.

\section{REFERÊNCIAS}

1. Lei $\mathrm{n}^{\circ}$ 12.711, de 29 de Agosto de 2012. Dispõe sobre o ingresso nas universidades federais e nas instituições federais de ensino técnico de nível médio e dá outras providências. Presidência da República, 
2012.

2. ANDIFES. Associação Nacional dos Dirigentes das Instituições Federais de Ensino Superior. V Pesquisa do perfil dos graduandos das universidades federais. [Internet]; 2019. [Acesso em: 10 jun. 2020] Disponível em: http://ufes.br/sites/ default/files/ANEXO2/v_pesquisa_do_perfil _dos_graduandos_16_de maio.pdf.

3. Santos H, Souza, MG, Sasaki K. O subproduto social advindo das cotas raciais na educação superior do Brasil. Rev Bras Estud Pedagog. 2013; 94(237):542-63.

4. Dias Sobrinho J. Democratização, qualidade e crise da educação superior: faces da exclusão e limites da inclusão. Educ Soc. 2010; 31(113):1223-45.

5. Toassi RFC, Souza JM, Rösing CK, Baumgarten A. Perfil sociodemográfico e perspectivas em relação à profissão do estudante de Odontologia da Universidade Federal do Rio Grande do Sul, Brasil. Rev Fac Odontol Porto Alegre. 2011; 52(1/3):2532.

6. Cayetano MH, Gabriel M, Tavares J, Araújo ME, Martins JS, Michel-Crosato E, et al. O perfil dos estudantes de Odontologia é compatível com o mercado de trabalho no serviço público de saúde brasileiro? Rev ABENO. 2019;19(2):2-12.

7. Maia RS, Costa SM, Chagas PVF, Ferreira GE, Santos LMA, Fonseca AFP, et al. Indissociabilidade entre ensino, pesquisa e extensão do banco de instrumental odontológico: um relato de experiência. Rev Intercâmbio. 2016; 7:392-8.

8. Fonseca AF, Silva GG, Figueiro LGM, Pinto MQC, Chagas PVF. Banco de instrumental odontológico da Universidade Estadual de Montes Claros: um relato de experiência. Rev Intercâmbio. 2013; 4:253-9.

9. Teixeira MCB. Justiça social na formação em saúde (o que ocorre nos corredores universitários?). 1a ed. Curitiba: CRV; 2016.

10. Walker M, Unterhalter E. Amartya Sen's capability approach and social justice in education. USA: Palgrave Macmillan, 2007.

11. Universidade Federal Fluminense [Internet]; 2017. Pró-Reitoria de Graduação. Matriz Curricular da graduação em Odontologia. [Acesso em 20 ago. 2020]. Disponível em: https://app.uff.br/iduff/consultaMatrizCurric ular.uff.

12. Universidade Federal Fluminense - UFF em Números [Internet]; 2020. [Acesso em 20 ago. 2020]. Disponível em: http://www.uff.br/?q=node/6734/setores/seto res/node/grupo/setor/newsletter.

13. Nascimento TQ, Lucietto DA, Bastos MV, Silva AN. Perfil sociodemográfico de estudantes de Odontologia de uma universidade pública do estado do Rio de Janeiro". In: Anais da LVII Jornada Fluminense de Odontologia Professor Coelho e Souza; 22 e 25 Outubro de 2019; Niterói (RJ), Brasil. Niterói (RJ), Faculdade de Odontologia da Universidade Federal Fluminense; 2019.

14. Brasil. Ministério da Saúde. Agência Nacional de Vigilância Sanitária. Serviços Odontológicos: Prevenção e Controle de Riscos, Agência Nacional de Vigilância Sanitária. Brasília: Ministério da Saúde, 2006. $156 \mathrm{p}$.

15. Ristoff D. O novo perfil do campus brasileiro: uma análise do perfil socioeconômico do estudante de graduação. Avaliação. 2014; 19(3):723-47.

16. Carvalhaes F, Ribeiro CA. Estratificação Horizontal da educação superior no Brasil: desigualdades de classe, gênero e raça em um contexto de expansão educacional. Tempo Soc. 2019; 31(1): 195-233.

17. Buarque C. A universidade na encruzilhada. 
In: Seminário: por que e como reformar? Brasília: Unesco; Brasil; Ministério da Educação, 2003.

18. Morita CM, Amante CJ, Tanaka EE, Porto NA, Hayassy A, Miguel LCM, Hyppolito CA et al. Instrumentais odontológicos essenciais para a graduação em Odontologia. Rev ABENO. 2016;16 (supl. 1):3-35.

19. Martins AB, Menezes IH, Queiroz MG. Estudantes de odontologia cotistas e o instrumental odontológico. Rev ABENO. 2019; 19(3): 58-68.

20. Walker M. Higher Education Pedagogies - A Capabilities Approach. England: Open University Press, 2006.

21. Finkler M, Negreiros DP. Formação $x$ educação, Deontologia x ética: repensando conceitos, reposicionando docentes. Rev ABENO. 2018; 18(2): 37-44.
22. Siqueira VHF, Fonseca MCG, Sá MB, Lima ACM. Construções identitárias de estudantes de farmácia no trote universitário: questões de gênero e sexualidade. Pro-Posições. 2012; 23(2):145-59.

23. Rios IC, Schraiber LB. A relação professoraluno em Medicina: um estudo sobre o encontro pedagógico. Rev Bras Educ Med. 2012; 36(3):308-16.

24. Puig JM, Martín X. Para um currículum de educación em valores. Folios. 2015; 41:7-22.

\section{Correspondência para:}

Andréa Neiva da Silva

e-mail: andreaneiva@id.uff.br

Departamento Saúde e Sociedade, Instituto de Saúde Coletiva da Universidade Federal Fluminense

Rua Marquês do Paraná, $303 \quad 3^{\circ}$ andar

Prédio Anexo ao HUAP

24033-900 Niterói/RJ 